\title{
Word-of-Mouth (WOM) distribution and intensity after elective surgery in relation to the decisive hospital choice process, satisfaction and recommendation
}

Jan-Henrik Schiff ( $\square$ j.schiff@klinikum-stuttgart.de )

https://orcid.org/0000-0001-5290-1503

Hanna Streiter

Philipps-Universitat Marburg Fachbereich Medizin

Katrin Eichstedt

Klinikum der Landeshauptstadt Stuttgart

Sören Wagner

Klinikum Stuttgart

Andreas Walther

Klinikum der Landeshauptstadt Stuttgart

Leopold J. H. Eberhart

Philipps-Universitat Marburg

Research article

Keywords: word-of-mouth, patient satisfaction, hospital choice, recommendation

Posted Date: February 18th, 2020

DOI: https://doi.org/10.21203/rs.2.23840/v1

License: (c) (i) This work is licensed under a Creative Commons Attribution 4.0 International License.

Read Full License 


\section{Abstract}

Background Patients frequently use experience-based sources when choosing a hospital, most often in form of word-of-mouth (WOM), which is perceived to be independent of direct information from providers. There is scarce data on the prevalence and intensity of WOM in the medical context.

Methods This exploratory cohort study recruited patients for elective surgery at two maximum care facilities. In addition to demographic data, information sources used and determinant factors for decisive hospital choice were evaluated. After hospital discharge, a telephone interview was used to inquire about the state of health, complications, overall satisfaction, the extent and intensity of positive and negative communication and the estimated number of people reached by WOM.

Results 348 questionnaires were evaluated and 231 patients were reached by telephone. Main sources for the hospital choice were the GP/specialist doctors, family and friends. Decisions were eventually based on the GP/specialist doctors, the hospital reputation and the spectrum of care provided by the hospitals. Post discharge, 94 patients were satisfied, 30 dissatisfied (107 neutral) with the care provided. After the operation, 120 had had contact with their GP/specialist doctors, 226 to family and friends, 129 to others, including 105 responses to the hospital staff. Postoperative persisting pain and a slow recovery to normal function were associated with lower satisfaction scores $(p<0.05)$. Satisfied patients had given mostly positive (ratio 11.6: 1), neutral predominantly positive (ratio 2.2:1), dissatisfied rather negative (ratio 1:1.2) information to others. Per patient, positive aspects were passed on to 12, negative to 4 persons. All satisfied and $46.7 \%$ of dissatisfied patients would recommend the hospital to their family and friends.

Conclusion WOM was found to correlate to satisfaction, with different proportions of positive and negative communication along the satisfaction continuum. Overall, the communication of positive aspects dominates

\section{Background}

Patients are increasingly appearing as informed and autonomous users in the healthcare system. They want to be involved in the decision-making process of the hospital choice or even want to choose the service provider themselves, in particular for elective procedures. [1-4]

Healthcare providers will need to take this into account, since approximately $63 \%$ of interventions/operations are elective (in Germany).[5] To elect a hospital, Patient choose from numerous available information sources.[1, 6] Which sources patients use has been already subject of various studies. [7-12]

Patients search the Internet, use quality reports and certificates and decide, taking other factors such as proximity of the hospital to the place of residence, spectrum of care and the qualification of the 
physicians in to account. $[1,13]$ These publicly available information-sources are meant to be independent, relevant, and publicly accessible.[1]

However, some of the problems concerning these sources are that at the time of the hospital's choice, patients often are unaware of their existence, fail to understand their meaning, or they do not consider the information relevant for their choice.[1]

Therefore patients often rely on their own experience (i.e. in the context of an outpatient consultation), opinions of family members, friends and recommendations of their GP or specialist doctors when choosing a hospital. While these direct experience-based sources do not necessarily meet the above mentioned criteria, they are given high priority by patients:

Fact is that health services are often associated with high individual risks, while the quality seems difficult to judge.[14, 2] In addition, a medical treatment cannot easily be "returned" case of displeasure or meaningful problems. [3]

The direct experience-based sources are considered part of the "word-of-mouth" (WOM) propaganda. WOM is said to be one of the most influential channels of communication as it is received from 'people like me', where the receiver perceives the WOM-giver to be non-commercial, in contrast to marketer initiated communications, and it is therefore given high credibility. $[15,1,16-18,2,19,20]$ This form of communication is not limited to face-to-face communication, and people known through networks might also be included.[21] [22]

The group of so-called influencers is considered a gray area and is merely active in the area of product advertising and placement.[22]

Service providers have only little influence on the dissemination of these quality information sources (WOM) as these channels tend to be outside of their spectrum of communication.

WOM communication is affected by satisfaction and empathy,[23] further, a close connection between the channels used for WOM communication and satisfaction seems likely.[21] In addition, it also seems likely that for WOM communication after hospital discharge similar channels are being used as in obtaining information and the decision making process for the hospital choice. [2]

There are studies showing that dissatisfied will distribute their experiences about eleven times, while satisfied do this only six times,[24] in other studies this ratio is $20: 8 .[25,26]$

Data in the medical context are scarce, the available studies focus on the developmental processes of WOM. However, there are no studies on the prevalence and intensity of WOM in the field of operative medicine.[2] 
As yet, for the situation of an elective operation it is uncertain how exactly WOM communication after discharge relates to the sources of information used during hospital choice or to satisfaction, the direction and the frequency of WOM propaganda post discharge has not been addressed in the medical context.

Therefore, the aim of our exploratory study was the investigation of

- the sources of information accessed, as well the determination of the factors that had the strongest impact on the decision making

- global satisfaction and factors that may alter satisfaction a few weeks after discharge

- the direction of WOM propaganda and its relation to satisfaction, WOM frequency, recipients and possible number of persons reached

- the willingness of patients to recommend the service provider.

\section{Methods}

Ethics approval and consent to participate and Consent for publication

After approval by the Research Ethics Committee ( $N^{\circ} \mathrm{F} 2012-014$, Ehical commission of the federal medical board of Baden-Württemberg), patients were included after written informed consent was obtained from all individual participants included in the study at a university hospital (1100 beds) and a tertiary care teaching hospital (1200 beds).

Patient inclusion criteria were age over 16 years, ability to speak, read and write German, minor elective procedures (arthroscopies, herniotomies, minor ENT surgery etc.) under general anaesthesia. Eligible patients were identified by the clinic information system during the period of November 2015 to June 2017.

Using a questionnaire, demographic data, chronic and other medical conditions as well as the information sources used to choose the hospital were obtained [27] [7-12] 
Information sources were divided in sources with direct contact/interaction to other people and other, publicly accessible information sources. Direct information givers were the GP/specialist doctors, Family/Friends, Hospital employees or the surgeons, Internet chats, support groups, people from other (referring) hospitals or nursing homes or the health insurance company.

Publicly accessible information sources were general information over the Internet (Blogs, general information on hospital sites etc.), information via TV or Radio, and campaign information in newspapers or informative presentations for patients. If patients already had own experiences with the hospital, this was treated as a separate entity.

Patients were asked to choose up to three factors that had major influence on their choice of the hospital. Questionnaires were returned by internal mail or collected by the study persons in an opaque envelope.

Two study persons trained in telephone interviewing contacted all patients for a semi-structured interview by telephone three to four weeks after hospital discharge.

Patients were asked about the postoperative course, medical problems since discharge and postdischarge satisfaction was assessed at the end of the interview on a scale from 0-10. High satisfaction was considered 2 standard deviations (SD) and mere satisfaction 1 SD above the mean. In general, dissatisfaction was considered with mere dissatisfaction 1 SD, dissatisfaction 2 SD and strong dissatisfaction 3 SD below the mean. The remainder were considered as neutral.[28, 29]

To assess the frequency of communication events (contacts) with other people about their hospital experience, patients were prompted to think about how often they had had contact to the hospital staff (doctors, nurses, others), to their GP/specialist doctors, friends or family or had used social media to rate the frequency of these communication events. While patients will tell experiences repeatedly to the same person (contact), they might reach a group of persons with just one communication contact, thus Patients were also asked to estimate the number of people they had reached to share their positive or negative experiences. Calculation of events for the three satisfied groups was done by multiplying the number of patients that communicated positively or negatively in each group with the median of the events. The number of people reached by WOM was calculated in proportion to the group sizes.

The final (ultimate) question was whether patients would recommend the hospital to their families and friends.[30, 31]

\section{Statistical analysis}

For statistical analysis SPSS (SPSS 24.0, SPSS Inc. Chicago, Illinois) and Excel (Microsoft ${ }^{\circledR}$ Excel XP, Microsoft Corp. Redmond, Washington) were utilised. 
Using the information given in previous publications on satisfaction, we calculated 140 questionnaires in to find significant differences between satisfied groups with an $\alpha=0.05$ and a $\beta=0.1$. $[32,28,33]$

Effect of single influencing factors was determined by the student-t test, for ordinal data and scores, nonparametric tests were applied. Correlations were made by correlation coefficients (Pearson $r$ or the Spearman correlation). A $p<0.05$ was considered statistically significant.

The ratio for positive and negative WOM was calculated for each group of satisfied, neutral and dissatisfied patients by using the mean number of events as estimated by the patients. Positive events communicated to other people served as the numerator and the number of negative events communicated as the denominator, the same accounts for the estimates of people reached with WOM.

Due to absence of normal distribution (Shapiro-Wilk test) and large scattering of values, the median was used to calculate the communication frequencies. The actual number of persons in the satisfaction groups was calculated in relation to the respective group size.

\section{Results}

With a rate of $77 \%, 348$ patients returned the assigned questionnaire. 231 Patients were finally available for the telephone interviews, some patients had to be contacted several times. No differences with regard to demographic data found for the group that was unavailable for the interview. (Table 1) Information sources and choice of hospital Patients had used up to seven different source of information (median 2), more than $90 \%$ relied on a maximum of 3 sources. Patients had used mainly experienced based sources: $328(94 \%)$ had sought direct advice or opinion from another person, mainly their GP / specialist doctor (72\%), followed by family/friends. Over one third (134 (38.4\%)) had used publicly available sources, $26 \%$ (91) had relied on own previous experiences as information sources. (Table 2) For the final choice of the hospital, most Patients (227 (65.2\%)) had relied on their GP, followed by information provided by their Family or Friends (82 $(23.6 \%))$. Other factors belonging to the group of publicly available sources were the hospitals reputation (107 (30.7\%)), spectrum (104 (29.9\%)) as well as the location of the hospital (91 $(26,1 \%))$. The information coming directly from the GP/specialist doctor, Family/Friends or from a hospital medical person (including the surgeon) were found to have the strongest impact on the choice of hospital. Personal information from the Internet (Chat/Blogs etc.) did not have this effect, the same accounts for publicly available information from the Internet or other sources. Medical expertise was found to be an important factor, ranking first or second. (Table 2) Satisfaction With a standard deviation of 1.9 and a median of 8 (mean 7.9) 94 (40.6\%) were considered merely to highly satisfied (score >8), 30 dissatisfied (score $\leq 6,13 \%$ ) and 107 neutral (score $>6$ to $<8,46.3 \%$ ). (Table 3) Preoperative fatigue $(p=0,002)$, and the post op factors persisting pain $(p=0,012)$ and a slow recovery to normal function $(p=0.008)$ were associated with lower satisfaction scores. Word Of Mouth -Communication $120(52 \%)$ stated they had had contact with the GP/specialist doctors, 226 (97.8\%) with family and friends and 129 $(55.8 \%)$ with other people, often several times. The communication frequencies were to the 
$\mathrm{GP} /$ specialists doctors 1 (median), to family/friends about 14 and 3 to others. Only two patients stated to have communicated via Internet forums, one with a hospital liaison committee, two with a support group alongside non-specific mentionings (clients, colleagues, etc.). 105 (45.5\%) patients had given feedback directly to hospital staff, a single patient had used a hospital web side to provide feedback. (Table 3 ) Overall, 218 (94.3\%) patients stated to have passed on positive aspects of their hospital experience, 82 (35.3\%) (also) negative (ratio 2.7: 1). Satisfied patients had given more positive than negative (ratio 11.6: 1), neutral predominantly positive (ratio 2.2:1), dissatisfied rather negative (ratio 1:1.2) information to others. In relation to satisfaction, the answer given to ultimate question differed significantly, were all of the satisfied group said they would recommended the hospital to family and friends, dissatisfied in only $46.6 \%(p<0.001)$. (Table 3 ) Based on the estimates of people reached with WOM, we calculated satisfied patients to have reached 17 people with positive compared to 2 with negative aspects of their care, while in the group of dissatisfied patients this ratio was 7:9. On average, more than 12 different people had received positive and about 4 negative WOM from one patient (ratio 3:1). (Table 3)

\section{Discussion}

Our exploratory study is the first to link elective information acquisition, hospital choice decision making, WOM communication frequency and communication channels as a function of satisfaction for elective, smaller operations. Our patients had used mainly experienced based sources during the decisive process with information from their GP / specialist doctor ranking first, followed by family/friends. WOM distribution followed the routine contact frequency in hospital and after discharge. In hospital, nurses and non-medical personnel were contacted most frequently, post discharge family/friends. About $40 \%$ were satisfied and would recommend the hospital, while of the $13 \%$ dissatisfied only $46.6 \%$ would recommend the hospital to family/friends. Overall, positive WOM dominated, satisfied patients had given rather positive than negative (ratio 11.6: 1) but dissatisfied more negative (ratio 1:1.2) information to others.

Patients independently use various sources for the choice of the hospital, they make particularly use of the WOM concept that is based on trust and experience. $[1,3,4,2]$ What's new is that the most common way of passing on the hospital experience is by talking to family and friends, the GP/specialist and the hospital staff in analogy to the contact frequency. Overall, positive WOM communication predominates while there are major differences between satisfied and dissatisfied patients.

The most commonly used sources for hospital choice in our study are consistent with previous surveys of planned [4] or actually used information sources.[1]

However, patients in our study relied mainly on information from the GP/specialist followed by the reputation of the hospital. The reason might be that the implementation of our study at two maximum care facilities. 
Depending on the sources of information, experience-based information did have the major impact in the decision-making process, often with inclusion of additional medical expertise.

The assumption that patients would communicate satisfaction in analogy to the decision-making process may only be confirmed in terms of the experience-based sources, although the conditions seem reversed, were significantly more patients used the advice of the GP/specialist as a primary source but had postoperatively communicated more often with family and friends. This does not come as a surprise given that the groups of people that patients routinely make contact to after hospital discharge are the ones who appear to receive most information. Given this, the contact frequency to family and friends naturally was highest, followed by non-medical clinic personnel and the hospital doctors, GPs as well as specialists.

The communication about different aspects of the treatment starts in hospital, were patients stated to frequently have informed hospital personnel about their experiences. Here, it is possible to assess satisfaction aspects at an early stage and on-site, in order to identify quality-relevant deficiencies and to implement appropriate measures. [3] Furthermore, at this stage, management of dissatisfaction may impact on post discharge WOM behavior.

These are important findings, since hospitals have little impact on WOM after discharge and interventions concerning aspects of satisfaction may be initiated early and in hospital.

Feedback in social networks or on websites may account for up to $18 \%$ of communication,[34] in our study only two patients used this possibility to give positive feedback. It may be that the Internet use takes place later than in our investigated period, or that the operations under investigation are not distributed frequently over the Internet.[2] Overall, dissatisfied patients choose similar ways for communication as satisfied ones.

We have found lower satisfaction in patients with persistent pain or a slow recovery to normal function, two indicators of abnormal healing processes. Preoperative fatigue may alter patients' expectations and therefore exert impact on satisfaction in our study.

Satisfaction and dissatisfaction can be considered different constructs, the "two-factor theory".[35] Within this concept, some facets of the care produce satisfaction, while other facets produce dissatisfaction, even in the same patient. This effect has been described using satisfaction questionnaires, were neither of the questionnaires reported total satisfaction nor dissatisfaction. [36, 32, 28] 
The theory on asymmetrical effects suggests that negative events produce a stronger effect by signalling that action needs to be taken and proportionally more dissatisfied people are expected to engage in WOM. [37] Our findings suggest otherwise and most patients stated that they had passed on positive aspects of their stay and treatment, and satisfied patients reported a higher contact frequency. Several factors may be responsible: First, most patients are thankful when surgery and anesthesia are over. In addition, it is unusual address negative or unpleasant factors directly, as long as the patients are not extremely dissatisfied.[38] Here, the so-called social desirability may influence behavior, while there are further studies that support our findings: in the "Polyanna principle", pleasantness predominates and positive aspects are more accessible after exposition to pleasant events ("positivity bias"). Individuals strive for interpretation in positive terms to minimize negative aspects, in extreme cases leading to denial. [37]

There might a negative association in the lower and a positive in the higher part of the satisfaction continuum as in our study. In this concept, the relationship changes at a point located within a "zone of indifference", [39] were expectations and experiences match and no particular reaction is to be expected., an effect that was observable in our study. [40]

Hence, WOM communication itself cannot be considered as an indicator of the degree of satisfaction. [2]

The degree of satisfaction was determined in analogy to previous studies by means of the mean and the SD. $[28,29]$ Even though other classifications could be feasible, all satisfied respondents of our study would recommend the hospital, in the group of dissatisfied this was only $46 \%$ while considering WOM communication, we found a 'zone of indifference', [39] supporting the structure of the study.

\section{Limitations}

Satisfaction is an extremely complex construct of many items,[41,23] dependent on many influencing factors.[31]

Therefore, it should be assumed that the global satisfaction measures can only serve as a rough guide. While care was taken to maintain a specific order in the telephone interview that would link the events to the satisfaction query, there may be other factors not accounted for in this study, which could exert further influence. [4] However, as expected by various WOM theories, a relationship between WOM and satisfaction was found.[14, 40, 37, 39]

While the WOM communication channels were clearly addressed and we are able to report proportions of positive and negative WOM, there remains a degree of inaccuracy due to the design of the study, were the data were collected retrospectively in the telephone interview and the frequency of WOM communication as well as the number of people reached were estimated. However, a prospective design, unless disguised, could have distorted the results in terms of social desirability and recruitment would have been 
complicated by the fact that patients could have felt observed and may be refrained from communicating negative aspects.

WOM is frequently appearing as a component of a broader concept, such as loyalty, as it may transports more than just the explicit message. As in any other conversation, more components are involved such as valence (leading to different message and delivery characteristics), emotive (vividness, and strength of advocacy) and cognitive aspects. With our study design we were unable to assess specific contents or components that may have been transported during WOM on the givers side and to what effect on the recipients end, were negative WOM might be more emotionally charged and associated with dissatisfaction than positive and almost twice as likely to affect the recipient's opinion.[42]

In addition, drivers of Word of Mouth (WOM) (i.e. social- and self-motives, individuals with higher socially oriented values vs. other) other than the listed sentinel events were not examined. [42]

\section{Conclusions}

Our exploratory study is the first to link elective information acquisition, hospital choice decision making, WOM communication frequency and communication channels as a function of satisfaction for elective, smaller operations. For information and during the decisive process patients mainly had relied on experienced based sources. WOM distribution followed the routine contact frequency in hospital and after discharge. WOM was found to correlate to satisfaction, with different proportions of positive and negative communication along the satisfaction continuum. Overall, the communication of positive aspects dominates, only dissatisfied patients communicated more negative aspects than positive. The same accounts for the number of people that were reached with WOM: we calculated satisfied patients to have reached 17 people with positive compared to 2 with negative aspects of their care, in the group of dissatisfied patients this ratio was 7:9.

\section{Declarations}

Acknowledgements

- Not Applicable 
- Ethics approval and consent to participate and Consent for publication

See Text: After approval by the Research Ethics Committee (Ethik-Kommission der Landesärztekammer Baden-Württemberg (Ethic Commission of the Federal Medical Council BadenWuerttemberg) $N^{\circ} \mathrm{F}$ 2012-014), patients were included after written informed consent was obtained from all individual participants included....

- Availability of data and materials: The datasets during and/or analysed during the current study available from the corresponding author on reasonable request.

- Competing interests: None

- Funding: None

- Authors contribution:

All authors contributed to the study conception and design. Study design (JHS, LJHE), Material preparation (JHS, KE, HS), data collection (KE, HS) and analysis (JHS, LJHE, KE, HS, SW) were performed. The first draft of the manuscript was written by JHS and AW and all authors commented on previous versions of the manuscript. All authors read and approved the final manuscript.

\section{References}

1. de Cruppe W, Geraedts M. [How do patients choose a hospital for elective surgery?]. Bundesgesundheitsblatt Gesundheitsforschung Gesundheitsschutz. 2011;54(8):951-7. doi:10.1007/s00103-011-1320-3.

2. Martin S. Word-of-mouth in the health care sector: a literature analysis of the current state of research and future perspectives. International Review on Public and Nonprofit Marketing. 2012;14(1):35-56. doi:DOI 10.1007/s12208-016-0154-y.

3. Dierks ML, Bitzer EM, Lerch M, Martin S, Röseler S, Schienkiewitz A et al. Patientensouveränität: der autonome Patient im Mittelpunkt. Arbeitsbericht der Akademie für Technikfolgenabschätzung in Baden-Württemberg. 2001(195).

4. Dietrich M, Gapp O. Qualitätsinformationen von Krankenhäusern: Eine Untersuchung ihrer Relevanz und Anforderungen aus Patientensicht. . Zeitschrift für öffentliche und gemeinwirtschaftliche Unternehmen: ZögU / Journal for Public and Nonprofit Services. 2005;28(211-233). doi:10.2307/20765315. 
5. Hinz V, Drevs F, Wehner J. Electronic word of mouth about medical services. HCHE Research Paper. 2012(05).

6. Leister J, Stausberg J. Why do patients select a hospital? A conjoint analysis in two German hospitals. J Hosp Mark Public Relations. 2007;17(2):13-31. doi:10.1300/J375v17n02_03.

7. Damman OC, Hendriks M, Rademakers J, Delnoij DM, Groenewegen PP. How do healthcare consumers process and evaluate comparative healthcare information? A qualitative study using cognitive interviews. BMC Public Health. 2009;9:423. doi:10.1186/1471-2458-9-423.

8. Faber M, Bosch M, Wollersheim H, Leatherman S, Grol R. Public reporting in health care: how do consumers use quality-of-care information? A systematic review. Med Care. 2009;47(1):1-8. doi:10.1097/MLR.0b013e3181808bb5.

9. Howell MD. A 37-year-old man trying to choose a high-quality hospital: review of hospital quality indicators. JAMA. 2009;302(21):2353-60. doi:10.1001/jama.2009.1684.

10. Schneider EC, Epstein AM. Use of public performance reports: a survey of patients undergoing cardiac surgery. JAMA. 1998;279(20):1638-42.

11. Schwartz LM, Woloshin S, Birkmeyer JD. How do elderly patients decide where to go for major surgery? Telephone interview survey. BMJ. 2005;331(7520):821. doi:10.1136/bmj.38614.449016.DE.

12. Streuf R, Maciejek S, Kleinfeld A, G. B, M. R, Selbmann HK. Informationsbedarf und Informationsquellen bei der Wahl eines Krankenhauses. Gesundheitsökonomie \& Qualitätsmanagement. 2007;12(2):113-20.

13. Dietrich M, Gapp O, Grapp O. Qualitätsinformationen von Krankenhäusern: Eine Untersuchung ihrer Relevanz und Anforderungen aus Patientensicht. Zeitschrift für öffentliche und gemeinwirtschaftliche Unternehmen: ZögU/Journal for Public and Nonprofit Services. 2005;28(3):211-33.

14. Ferguson RJ, Paulin M, Bergeron J. Customer sociability and the total service experience: Antecedents of positive word-of-mouth intentions. Journal of service management. 2010;21(1):2544.

15. Coulter A, Jenkinson C. European patients' views on the responsiveness of health systems and healthcare providers. Eur J Public Health. 2005;15(4):355-60. doi:10.1093/eurpub/cki004.

16. Kurz RS, Wolinsky FD. Who picks the hospital: practitioner or patient? Hosp Health Serv Adm. 1985;30(2):95-106.

17. Scheibler F, Janssen $C$, Pfaff H. [Shared decision making: an overview of international research literature]. Soz Praventivmed. 2003;48(1):11-23.

18. Sloane G, Tidwell P, Horsfield M. Identification of the decision maker for a patient's hospital choice: who decides which hospital? J Hosp Mark. 1999;13(1):57-77. doi:10.1300/J043v13n01_04.

19. Allsop DT, Bassett BR, Hoskins JA. Word-of-mouth research: principles and applications. Journal of advertising research. 2007;47(4):398-411. doi:10.2501/S0021849907070419. 
20. Mazzarol T, Sweeney JC, Soutar GN. Conceptualizing word-of-mouth activity, triggers and conditions: an exploratory study. European Journal of Marketing. 2007;41(11/12):1475-94.

21. Söderlund M. Customer satisfaction and its consequences on customer behaviour revisited: The impact of different levels of satisfaction on word-of-mouth, feedback to the supplier and loyalty. International journal of service industry management. 1988;9(2):169-88.

22. Froitzheim UJ. Mundpropaganda. brand eins thema. 2019 Januar 2019:14-7.

23. Chaniotakis IE, Lymperopoulos C. Service quality effect on satisfaction and word of mouth in the health care industry. . Managing Service Quality: An International Journal. 2009;19(229-242).

24. Hart WL, Heskett JL, Sasser WEJ. "The profitable art of service recovery". Harvard Business Review. 1990;July-August:148-56.

25. . Fortune. 1990;December 11.

26. Fisk TA, Brown CJ, Cannizzaro KG, Naftal B. Creating patient satisfaction and loyalty. J Health Care Mark. 1990;10(2):5-15.

27. Jenkinson C, Layte R, Jenkinson D, Lawrence K, Petersen S, Paice C et al. A shorter form health survey: can the SF-12 replicate results from the SF-36 in longitudinal studies? J Public Health Med. 1997;19(2):179-86.

28. Schiff JH, Fornaschon AS, Frankenhauser S, Schiff M, Snyder-Ramos SA, Martin E et al. The Heidelberg Peri-anaesthetic Questionnaire-development of a new refined psychometric questionnaire. Anaesthesia. 2008;63(10):1096-104. doi:10.1111/j.1365-2044.2008.05576.x.

29. Schiff JH, Russ N, Ihringer K, Heal C, Martin E, Walther A. Paediatric Perianesthesia questionnaire: development and data from eight hospitals across Germany. Br J Anaesth. 2011;106(1):88-95. doi:10.1093/bja/aeq297.

30. Reichheld F, Markey R. The Ultimate Question 2.0. Harvard Business Review Press; 2011.

31. Helmig B, Dietrich M. Qualität von Krankenhausleistungen und Kundenbeziehungen. BETRIEBSWIRTSCHAFT-STUTTGART. 2001;61(3):319-34.

32. Eberhart LHJ, Kranke P, Buendgen W, Simon M, Geldner G, Wulf H et al. Decelopment and evaluation of a new instrument enabling the patient to assess the perioperative phase (ppp questionnaire). Anest Intensivmed. 2004(45):436-45.

33. Schiff JH, Hüppe M, Möllemann M, Pützhofen G, Martin J, Schleppers A et al. Evaluated Anaesthesia Questionnaire: development of a Questionnaire to assess patients" experiences with anaesthesia. . Anästh Intensivmed. 2008;49:S25-S40.

34. Compete Hospital Study. Google. 2012. https://ssl.gstatic.com/think/docs/the-digital-journey-towellness-hospital-selection_research-studies.pdf. Accessed 01.04.2019.

35. Yi Y. A critical review of consumer satisfaction. In: ZeithamI VA, editor. A Review of Marketing. Chicago, IL.: American Marketing Association; 1990.

36. Barnett SF, Alagar RK, Grocott MP, Giannaris S, Dick JR, Moonesinghe SR. Patient-satisfaction measures in anesthesia: qualitative systematic review. Anesthesiology. 2013;119(2):452-78. 
doi:10.1097/ALN.0b013e3182976014.

37. Taylor SE. Asymmetrical effects of positive and negative events: the mobilization-minimization hypothesis. Psychol Bull. 1991;110(1):67-85.

38. Bowling A. Mode of questionnaire administration can have serious effects on data quality. J Public Health (Oxf). 2005;27(3):281-91. doi:10.1093/pubmed/fdi031.

39. Woodruff RB, Cadotte ER, Jenkins RL. Modeling Consumer Satisfaction Processes Using ExperienceBased Norms. . Journal of Marketing Research. 1983;20(20):296-304. doi:10.2307/3151833.

40. Magnus S. Customer satisfaction and its consequences on customer behaviour revisited: The impact of different levels of satisfaction on word-of-mouth, feedback to the supplier and loyalty. International Journal of Service Industry Management,. 1998;9(2):169-88. doi:10.1108/09564239810210532.

41. Upadhyay S, Powers T. Do Attributes of Patient Satisfaction Affect Word-of-Mouth Communication? In: Stieler M, editor. Creating Marketing Magic and Innovative Future Marketing Trends.

Developments in Marketing Science: Proceedings of the Academy of Marketing Science.: Springer, Cham; 2017. p. 867-78'.

42. Sweeney JC, Soutar GN, Mazzarol T. Word of mouth: measuring the power ofindividual messages. European Journal of Marketing. 2012;46(172):237-57.

\section{Tables}

Table 1 Demographic data 


\begin{tabular}{|c|c|c|}
\hline & $\begin{array}{l}\text { Total } \\
\mathrm{n}=348\end{array}$ & $\begin{array}{c}\text { Telephone interview } \\
\qquad \mathrm{n}=231\end{array}$ \\
\hline ;ex; M / F (missing) & $156 / 190(2)$ & $102 / 129$ \\
\hline ıge; years (SD) & $49.27(15.66)$ & $49.8(15.61)$ \\
\hline \multicolumn{3}{|l|}{ ıge group n (\%) } \\
\hline$\leq 60$ years & 247 (70.9) & $161(69.7)$ \\
\hline$>60$ years & $95(27.3)$ & $65(28.1)$ \\
\hline missing & $6(1.7)$ & $5(2.2)$ \\
\hline \multicolumn{3}{|l|}{ Marital status n(\%) } \\
\hline single/divorced/widowed & $126(36.2)$ & $55 / 31(37.2)$ \\
\hline marired & 219 (62.9) & $143(61.9)$ \\
\hline missing & $3(1)$ & $2(0.9)$ \\
\hline \multicolumn{3}{|l|}{ Iducation } \\
\hline none & $5(1.4)$ & $1(0.4)$ \\
\hline $0-8$ years & $93(26.7)$ & $61(26.4)$ \\
\hline 9-10 years & 129 (37.1) & $86(37.2)$ \\
\hline $10-13$ years & $49(14.1)$ & $34(14.7)$ \\
\hline Postgraduate & 69 (19.8) & $47(20.3)$ \\
\hline missing & $3(0.9)$ & $2(0.9)$ \\
\hline
\end{tabular}

'hronic Diseases n (\%)

$\begin{array}{lcc}\text { Diabetes Mellitus } & 26(7.5) & 17(7.4) \\ \text { Pulmonary disease } & 41(11.8) & 24(10.4) \\ \text { Arthritis } & 53(15.2) & 33(14.3) \\ \text { Arterial Hypertension } & 77(22.1) & 56(24.2) \\ \text { Allergies } & 78(22.4) & 53(22.8) \\ \text { ng } & 93(27) & 55(24.2) \\ \text { l regularly (several times/week) } & 51(14.7) & 29(12.6)\end{array}$

jeneral health problems n(\%)

$\begin{array}{lcc}\text { Pain } & 146(42) & 94(40.7) \\ \text { Fatigue } & 98(28.2) & 70(30.3) \\ \text { Shortness of breath } & 41(11.8) & 25(10.8 \%)\end{array}$

Iealth self-assessment $\mathrm{n}(\%)$

$\begin{array}{lcc}\text { excellent } & 14(4) & 8(3.5 \%) \\ \text { very good } & 44(12.6) & 29(12.6 \%) \\ \text { good } & 185(53.2) & 121(52.4 \%) \\ \text { fair } & 94(27) & 28(27.7 \%) \\ \text { bad } & 8(2.3) & 6(2.6 \%)\end{array}$


Table 2 Information sources used in relation to decisive factors for the hospital choice

\section{Information source used for choice of hospital}

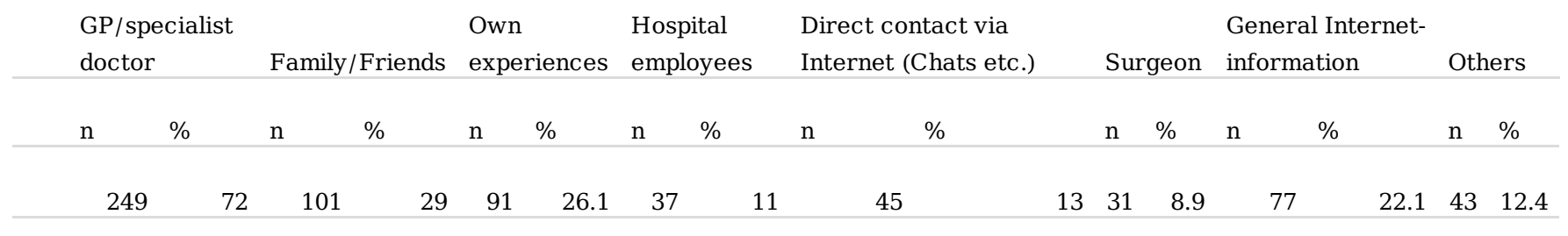

\section{tors for the hospital choice \\ n to source used)}

it

\begin{tabular}{|c|c|c|c|c|c|c|c|c|c|c|c|c|c|c|c|c|}
\hline & 211 & 84.7 & 47 & 46.5 & 51 & 56.0 & 12 & 32.4 & 21 & 46.7 & 15 & 48.4 & 47 & 61.0 & 22 & 51.2 \\
\hline nds & 51 & 20.5 & 64 & 63.4 & 25 & 27.5 & & & & & 9 & 29.0 & 19 & 24.7 & 14 & 32.6 \\
\hline & 53 & 21.3 & 26 & 25.7 & 58 & 63.7 & 15 & 40.5 & & & 13 & 41.9 & & & 10 & 23.3 \\
\hline
\end{tabular}

$19 \quad 51.4$

\begin{tabular}{|c|c|c|c|c|c|c|c|c|c|c|c|c|c|c|c|}
\hline & & & 25 & 24.8 & 32 & 35.2 & & & 13 & 28.9 & 20 & 64.5 & 17 & 22.1 & \\
\hline \multicolumn{16}{|c|}{ he } \\
\hline & 66 & 26.5 & 26 & 25.7 & 34 & 37.4 & 14 & 37.8 & & & 7 & 22.6 & 14 & 18.2 & \\
\hline & 82 & 32.9 & 37 & 36.6 & 27 & 29.7 & 14 & 37.8 & 15 & 33.3 & 7 & 22.6 & 28 & 36.4 & 1133.3 \\
\hline & 71 & 28.5 & 33 & 32.7 & 38 & 41.8 & 16 & 43.2 & & & 7 & 22.6 & 25 & 32.5 & $17 \quad 39.5$ \\
\hline & & & & & & & & & 23 & 51.1 & & & 39 & 50.6 & \\
\hline ! & & & & & & & & & 13 & 28.9 & & & 17 & 22.1 & \\
\hline
\end{tabular}

Multiple answers were frequent. as patients had used up to seven (median 2) different sources of information for the hospital choice, therefore sums greater $100 \%$ are possible, bold numbers give the highest decisive fraction for each group of used information.

Tabelle 3 Communication behavior, contact frequency and estimated number of people reached in terms of overall satisfaction 
Satisfaction (Interview)

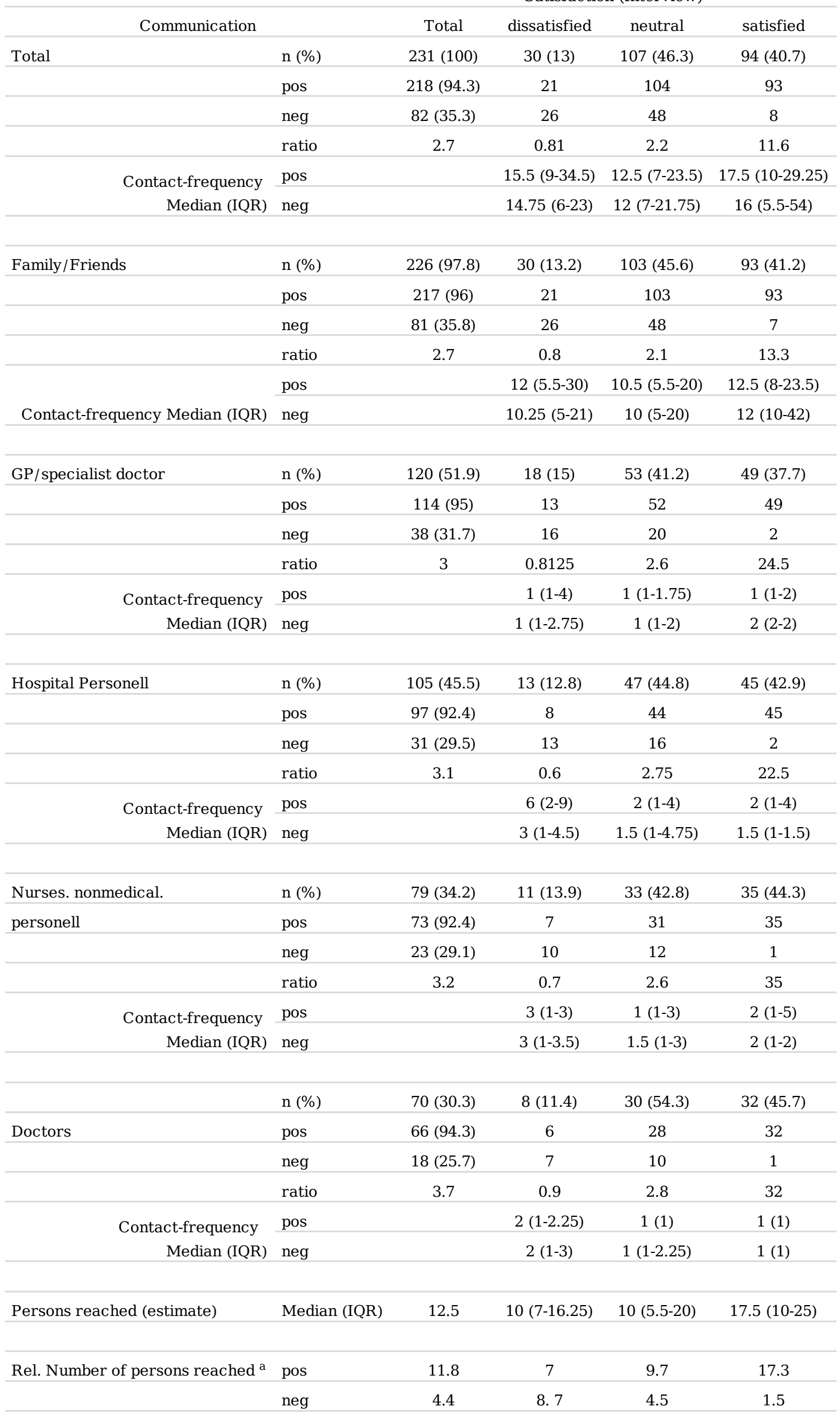

Page 17/18 
IQR (Interquartil Range).

${ }^{\text {a }}$ Relative Number of people reached: calculation used the proportion of patients in each satisfaction group communicating pos. or neg. multiplied with median of people reached in the respective satisfaction group 